\title{
Phylogenetic Relationships Within the Family Potyviridae: Wheat Streak Mosaic Virus and Brome Streak Mosaic Virus Are Not Members of the Genus Rymovirus
}

\author{
Drake C. Stenger, Jeffrey S. Hall, Il-Ryong Choi, and Roy French
}

First, second, and fourth authors: Agricultural Research Service, U.S. Department of Agriculture, and Department of Plant Pathology, University of Nebraska, Lincoln 68583; third author: School of Biological Sciences, University of Nebraska, Lincoln 68583. Accepted for publication 22 April 1998.

\begin{abstract}
Stenger, D. C., Hall, J. S., Choi, I.-R., and French, R. 1998. Phylogenetic relationships within the family Potyviridae: Wheat streak mosaic virus and brome streak mosaic virus are not members of the genus Rymovirus. Phytopathology 88:782-787.

The complete nucleotide sequence of wheat streak mosaic virus (WSMV) has been determined based on complementary DNA clones derived from the 9,384-nucleotide (nt) RNA of the virus. The genome of WSMV has a 130-nt 5' leader and 149-nt 3'-untranslated region and is polyadenylated at the 3' end. WSMV RNA encodes a single polyprotein of 3,035 amino acid residues and has a deduced genome organization typical for a member of the family Potyviridae (5'-P1/HC-Pro/P3/6K1/CI/6K2/VPg-NIa/NIb/CP-3'). Because WSMV shares with ryegrass mosaic virus (RGMV) the biological property of transmission by eriophyid mites, WSMV has been assigned to
\end{abstract}

ABSTRACT the genus Rymovirus, of which RGMV is the type species. Phylogenetic analyses were conducted with complete polyprotein or NIb protein sequences of 11 members of the family Potyviridae, including viruses of monocots or dicots and viruses transmitted by aphids, whiteflies, and mites. WSMV and the monocot-infecting, mite-transmitted brome streak mosaic virus (BrSMV) are sister taxa and share a most recent common ancestor with the whitefly-transmitted sweet potato mild mottle virus, the type species of the proposed genus "Ipomovirus." In contrast, RGMV shares a most recent common ancestor with aphid-transmitted species of the genus Potyvirus. These results indicate that WSMV and BrSMV should be classified within a new genus of the family Potyviridae and should not be considered species of the genus Rymovirus.

Additional keywords: proposed genus "Tritimovirus."
Wheat streak mosaic virus (WSMV) is an important pathogen of wheat (Triticum aestivum L.) that is transmitted by the eriophyid mite, Aceria tosichella Keifer (7). WSMV is currently classified as a member of the genus Rymovirus in the plant virus family Potyviridae $(33,36)$. Viruses of the family Potyviridae have been classified into genera that coincide with vector taxa (33). The numerous and economically important aphid-transmitted viruses belong to the genus Potyvirus (the type species is potato virus $\mathrm{Y}$ ) and are the most thoroughly characterized viruses of the family due to the numerous virus species for which complete sequences are available. During the past decade, it has become apparent that fungus-transmitted, bipartite viruses, such as barley yellow mosaic virus (BaYMV), share an evolutionary relationship with the aphid-transmitted potyviruses $(20,23)$ and are members of the genus Bymovirus (the type species is BaYMV) within the family Potyviridae. The whitefly-transmitted sweet potato mild mottle virus (SPMMV) is clearly a member of the family Potyviridae, and the genus "Ipomovirus" has been proposed, with SPMMV as the sole species proposed (12). Thus, for these three genera of the family Potyviridae, sequence comparisons have validated species affiliations within genera that group virus species transmitted by the same vector taxa.

Corresponding author: D. C. Stenger; E-mail address: dstenger@unlinfo.unl.edu

Mention of proprietary or brand names are necessary to report factually on available data; however, the USDA neither guarantees nor warrants the standard of the product, and the use of the name by USDA implies no approval to the exclusion of others that also may be suitable.

Publication no. P-1998-0526-02R

This article is in the public domain and not copyrightable. It may be freely reprinted with customary crediting of the source. The American Phytopathological Society, 1998.
It is the eriophyid mite-transmitted viruses that have been problematic with respect to defining phylogenetic relationships within the family Potyviridae. Mite-transmitted species of the family Potyviridae include ryegrass mosaic virus (RGMV [29]), wheat streak mosaic virus $(11,22)$, brome streak mosaic virus (BrSMV [17]), and Agropyron mosaic virus (AgMV [26]). The genus Rymovirus (the type species is RGMV) currently includes these four mitetransmitted species plus Hordeum mosaic virus (HoMV [26]), for which a vector has yet to be identified, and several other virus species that have been partially characterized $(19,36)$. Recently, based on analysis of coat protein (CP) and, in some cases, partial NIb sequences $(6,16,27,29)$, it has been suggested that the genus Rymovirus is not monophyletic and should be split into at least two genera in which RGMV, HoMV, and AgMV remain within the genus Rymovirus, whereas WSMV and BrSMV constitute a new genus within the family Potyviridae (27). However, in previous efforts, $<25 \%$ of the viral genomes were analyzed. Thus, the relationships among members of the genus Rymovirus remain uncertain. In this paper, we report the complete nucleotide sequence of the Sidney 81 isolate of WSMV and extend the phylogenetic analysis of the genus Rymovirus, using as data sets complete polyprotein and mature NIb sequences for three species of the genus Rymovirus and eight additional species of the family Potyviridae.

\section{MATERIALS AND METHODS}

Construction of WSMV cDNA clones. Virions of the Sidney 81 isolate of WSMV (8) were partially purified from wheat cv. Centurk by the minipurification method of Lane (21), except that the extraction buffer was $0.1 \mathrm{M} \mathrm{K}{ }_{2} \mathrm{H} / \mathrm{KH}_{2} \mathrm{PO}_{4}$, $\mathrm{pH} 8.4$, containing $1.4 \mathrm{M} \mathrm{NaCl}, 0.1 \%$ 2-mercaptoethanol, and $0.5 \% \mathrm{CHCl}_{3}$. WSMV RNA was recovered from virions by digestion with proteinase $\mathrm{K}$ in the presence of sodium dodecyl sulfate, followed by phenol/ 
chloroform extraction and ethanol precipitation. Polyadenylated viral RNA was purified further, using a PolyA Tract I mRNA isolation kit (Promega, Madison, WI). Complementary DNA (cDNA) was synthesized, using a Pharmacia Biotech (Piscataway, NJ) cDNA synthesis kit, with cloned moloney murine leukemia virus reverse transcriptase in the first-strand reaction and oligo dT or random hexamers as primers. Second-strand synthesis was accomplished with the Klenow fragment of DNA polymerase I. EcoRI/ NotI adapters were ligated to the dsDNA products of the secondstrand reaction and cloned into the EcoRI site of pACT2 (Clontech Laboratories, Palo Alto, CA). The cloned cDNA inserts initially were characterized by sequencing the termini, and selected inserts were subcloned into pGEM5Zf+ as NotI fragments. To obtain WSMV cDNA clones containing the $5^{\prime}$ end of the viral RNA, cDNA was prepared with the $5^{\prime} / 3^{\prime}$-RACE kit (Boehringer Mannheim, Indianapolis, IN), and the amplified polymerase chain reaction product was cloned into the pGEM-T vector (Promega).

Sequencing of the WSMV genome. Four overlapping cDNA clones encompassing the complete genome of WSMV (Fig. 1) were selected and used to construct nested deletions, using the Erase-a-Base kit supplied by Promega. Nested deletions were obtained in both directions for each clone, and the deletion derivatives served as sequencing templates. The complete nucleotide sequence of WSMV RNA was obtained for both strands, with an average redundancy of 4.2 determinations/nucleotide (nt). The complete WSMV sequence was compiled by the University of Wisconsin-Madison GCG program.

Similarity and phylogenetic analyses. Pairwise alignments of complete polyprotein sequences of selected potyviral genomes were conducted by the PILEUP function of GCG, with alignment parameters set at default values of gap weight $=12$ and gap length weight $=4$. The distribution of amino acid (aa) residue identity of each virus relative to WSMV or RGMV was determined by pairwise alignments, using the Sequence Similarity Presenter program (15) with a window size of 10 aa residues and a window shift of 2 aa residues. Multiple alignments of complete polyprotein or NIb protein sequences of 11 viruses of the family Potyviridae (listed in Table 1) were obtained using the PILEUP function of GCG, with alignment parameters set at default values. Parsimony and neighbor-joining analyses of amino acid sequence data were performed by PAUP 4.0.0d60, provided by D. Swofford (Smithsonian Institution, Washington, DC). Inferred gaps in the multiple alignments were treated as missing data. The heuristic search option was used to find and retain all most parsimonious trees for bootstrap-re-

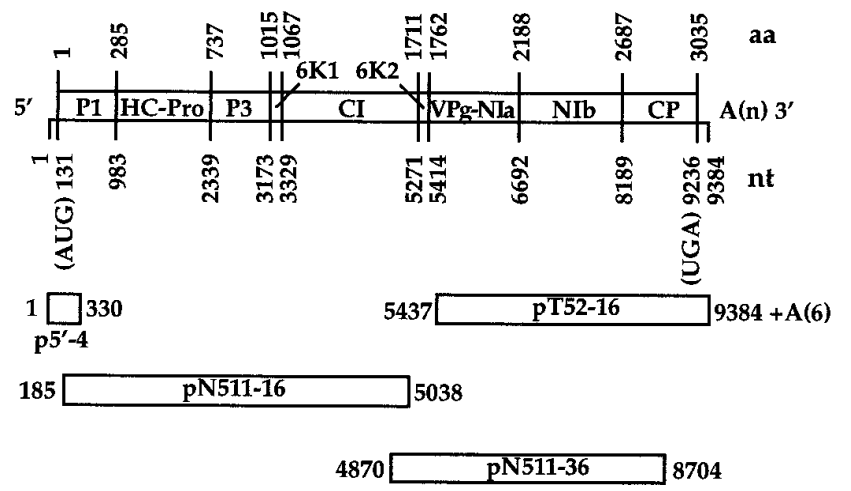

Fig. 1. Genome organization of wheat streak mosaic virus (WSMV). The map of the WSMV genome depicts the locations of polyprotein open reading frame start and stop codons, the amino acid (aa) and nucleotide (nt) coordinates of predicted proteinase cleavage sites delineating mature potyviral proteins ( $\mathrm{P} 1$, HC-Pro, P3, 6K1, CI, 6K2, VPg-NIa, NIb, and CP), and the relative locations and the nucleotide coordinates of complementary DNA (cDNA) clones used to determine the complete nucleotide sequence of WSMV. pT52-16 was obtained by oligo dT priming of the first-strand cDNA reaction; pN511-16 and pN511-36 were obtained by random hexamer priming of first-strand synthesis; and $\mathrm{p}^{\prime}-4$ was obtained by the $5^{\prime} / 3^{\prime}$-RACE procedure. sampled data sets based on 1,000 replications. A distance matrix of amino acid sequences was generated and used to infer neighbor-joining trees for nonresampled data sets or bootstrap-resampled data sets (1,000 replications). For both types of phylogenetic analyses, RNA 1 of BaYMV was defined as the outgroup.

\section{RESULTS}

Genome organization of WSMV. The complete nucleotide sequence of WSMV RNA is 9,384 nt, excluding the variable-length polyadenylated tail, and has been deposited in GenBank as accession AF057533. The genome of WSMV has the features of a typical potyvirus and consists of a single large open reading frame encoding a polyprotein of 3,035 aa residues flanked at the termini by a 130 -nt $5^{\prime}$ leader and a 149-nt 3'-untranslated region (Fig. 1). The $5^{\prime}$-leader sequence is A-T rich and devoid of $\mathrm{G}$ residues at the extreme $5^{\prime}$ end, as is common for other potyviruses for which $5^{\prime}$ leader sequences are known.

Examination of the WSMV polyprotein revealed potential viralencoded proteinase cleavage sites (Table 2; Fig. 1), similar to those characterized for tobacco etch virus (TEV [9,10,14,31]), that would result in production of mature proteins (P1, HC-Pro, P3, 6K1, CI, 6K2, VPg-NIa, NIb, and CP) that also are encoded by other species of the genera Rymovirus, Potyvirus, and "Ipomovirus". Two motifs that are conserved among all potyviruses, the polymerase motif of the NIb protein and the nucleotide binding motif of the CI protein, occur in the WSMV polyprotein sequence at the expected map positions (Fig. 2). In addition, the WSMV protein sequence contains a conserved 'GYCYM' pentapeptide motif beginning at amino acid position 623 within the carboxyterminal third of HC-Pro. A tyrosine residue at position 1843 of the peptide sequence occurs in the motif 'YGFDP,' matching exactly the context of the tyrosine, which forms the phosphoester linkage of TEV VPg to the 5' end of the viral RNA (28).

Similarity of potyviral polyproteins. Comparisons of polyprotein amino acid residue percent identity of WSMV and four other

TABLE 1. Potyvirus sequences used in similarity and phylogenetic analyses

\begin{tabular}{lllc}
\hline Virus species & Genus & $\begin{array}{l}\text { GenBank } \\
\text { Accession }\end{array}$ & Reference \\
\hline $\begin{array}{l}\text { Brome streak mosaic virus } \\
\text { Barley yellow mosaic virus }\end{array}$ & Rymovirus & Z48506 & 17 \\
$\quad$ RNA 1 & Bymovirus & X69757 & 23 \\
Johnsongrass mosaic virus & Potyvirus & Z26920 & 18 \\
Plum pox virus & Potyvirus & X16415 & 30 \\
Potato virus Y & Potyvirus & X12456 & 24 \\
Ryegrass mosaic virus & Rymovirus & Y09854 & 29 \\
Sweet potato mild mottle virus & "Ipomovirus" & Z73124 & 12 \\
Tobacco etch virus & Potyvirus & M15239 & 2 \\
Tobacco vein mottling virus & Potyvirus & X04083 & 13 \\
Wheat streak mosaic virus & Rymovirus & AF057533 & This paper \\
Zucchini yellow mosaic virus & Potyvirus & L31350 & 34 \\
\hline
\end{tabular}

a Current taxonomic status. Quotes indicate proposed genus.

TABLE 2. Predicted proteinase cleavage sites in wheat streak mosaic virus polyprotein

\begin{tabular}{llc}
\hline Proteinase & Peptide junction & Amino acid sequence $^{\mathrm{a}}$ \\
\hline P1 & P1/HC-Pro & GFITTY_S \\
HC-Pro & HC-Pro/P3 & KDYKIG_G \\
NIa & P3/6K1 & ELVEYQ_G \\
NIa & 6K1/CI & FNCEYQ_G $^{\text {b }}$ \\
NIa & CI/6K2 & SHVSYQ_A \\
NIa & 6K2/VPg-NIa & RSVKFE_G \\
NIa & VPg-NIa/NIb & DLVSWQ_S \\
NIa & NIb/CP & QYCVYE_S \\
\hline
\end{tabular}

${ }^{a}$ Underlined gap denotes peptide bond cleavage position.

b Amino acid residue 3 is hydrophobic, amino acid residue 5 is aromatic, and amino acid residue 6 is $\mathrm{Q}$ or $\mathrm{E}$. 
members of the family Potyviridae (Fig. 2A) clearly indicate that WSMV is a distinct virus species. The WSMV polyprotein was most similar to that of BrSMV, although extensive regions of the polyprotein have diverged even between these two mite-transmitted species. Interestingly, the WSMV polyprotein is no more similar to RGMV than it is to TEV. The polyprotein of RGMV is more similar to the polyprotein of TEV than to other potyviral polyproteins (Fig. 2B).

Based on the percent identity plots presented in Figure 2, it is apparent that certain regions of the potyviral polyprotein have diverged preferentially. NIb represents the most conserved region of the viral polyprotein, whereas the P1 region is the most divergent. Both observations agree with literature comparisons of potyviral sequence identities $(1,17,32,35)$. Among more closely related taxa (e.g., WSMV and BrSMV or RGMV and TEV), discontinuous clusters of high sequence identity $(<70 \%)$ occur in various regions of the polyprotein outside the NIb domain. In particular, WSMV and BrSMV share clusters of high sequence identity within the CI protein, the carboxy-terminal portion of HC-Pro, and the amino-terminal portion of P3 (Fig. 2A). RGMV and TEV also share clusters of high sequence identity within the CI, VPg-NIa, and $\mathrm{CP}$ regions (Fig. 2B). In contrast, RGMV and TEV share only three short stretches of high sequence identity in HC-Pro and none in P3.

The SPMMV polyprotein sequence is $\approx 28 \%$ identical to that of WSMV overall, with higher identities in the 6K1, CI, 6K2, VPg$\mathrm{NIa}, \mathrm{NIb}$, and $\mathrm{CP}$ regions and lower identities in P1, HC-Pro, and P3. However, residues 47 to 129 of WSMV P1 are 27 and $32 \%$ identical to P1 of SPMMV and BrSMV, respectively, and show no similarity to other potyviral polyproteins. Other notable sequence identities also are found in the amino-terminal portion of HC-Pro. The first 82 aa residues of the WSMV HC-Pro, corresponding to the region required for the aphid-transmission function of HC-Pro in the genus Potyvirus $(3,4)$, share no similarity with TEV or RGMV but are 37 and $32 \%$ identical to the corresponding HC-Pro regions of SPMMV and BrSMV, respectively.

Phylogenetic analyses of the family Potyviridae. Trees depicting the phylogenetic relationships among species of the family Potyviridae based on complete polyprotein (Fig. 3) or NIb protein (Fig. 4) sequences, using neighbor-joining or parsimony methods, consistently placed WSMV and BrSMV as sister taxa. For all

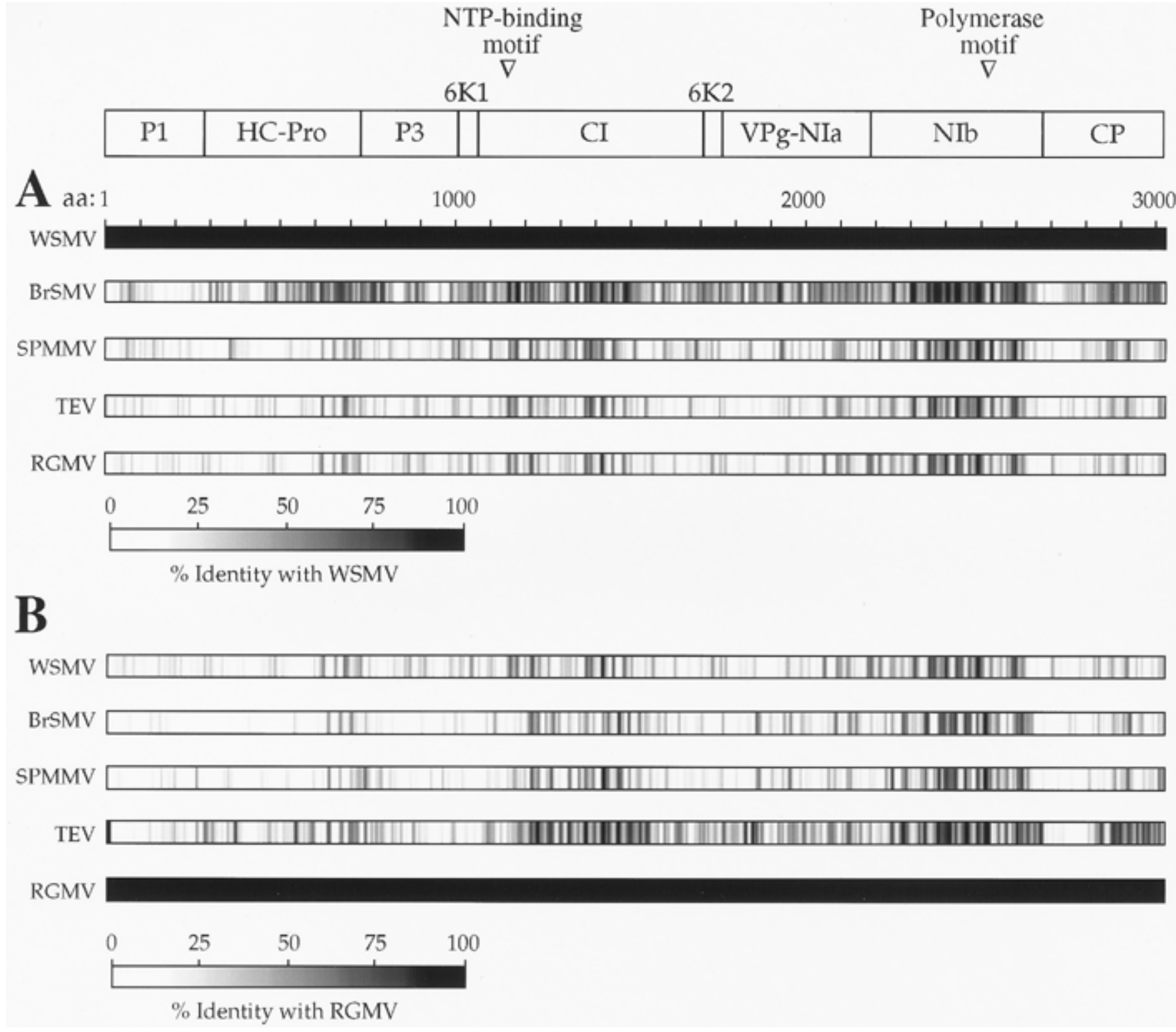

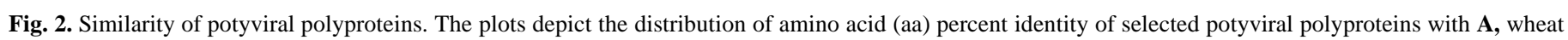

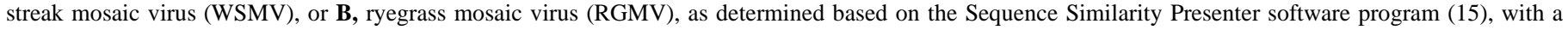

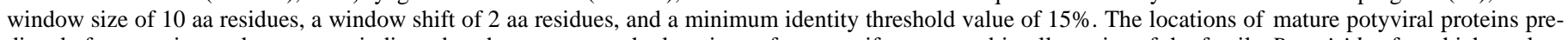

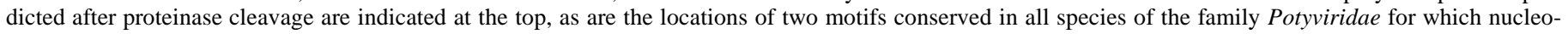
tide sequences are available. BrSMV = brome streak mosaic virus; SPMMV = sweet potato mild mottle virus; and TEV = tobacco etch virus. 
trees, regardless of the type of analysis performed, RGMV shared a most recent common ancestor with a clade containing all aphidtransmitted species of the genus Potyvirus. The specific arrangement of taxa within a clade containing all dicot-infecting species of the genus Potyvirus varied depending on the specific data set and analytical method. Nonetheless, all of the dicot-infecting species of the genus Potyvirus cluster in a single clade that shared a most recent common ancestor with the monocot-infecting species Johnsongrass mosaic virus.

In all but one of the trees, the separate clades containing RGMV or only WSMV and BrSMV did not share a common node above the base of the trees. In the lone exception, the bootstrap-resampled neighbor-joining tree based on NIb protein sequences (Fig. 4) resulted in a tree topology that grouped the WSMV-BrSMV clade with the clade containing RGMV at the first node above the base of the tree. However, support for this node was weak $(51 \%$ of the trees examined by bootstrapping) and barely above the threshold to appear in a 50\% majority-rule consensus tree. If this node were collapsed to yield a polytomy, the basal topology of the neighbor-joining bootstrap-resampled NIb tree would be identical to that obtained by parsimony methods performed on the same data set.

Neighbor-joining trees based on nonresampled data sets (Figs. 3 and 4), in which mean character distances among taxa were depicted by horizontal branch lengths, indicated considerable divergence among species of the family Potyviridae. Thus, the extent of divergence between the sister taxa BrSMV and WSMV was not unusual and was similar to that observed in the neighbor-joining analyses of nonresampled data sets for TEV and tobacco vein mottling virus, which clustered as sister taxa within the genus

\section{CURRENT GENUS}

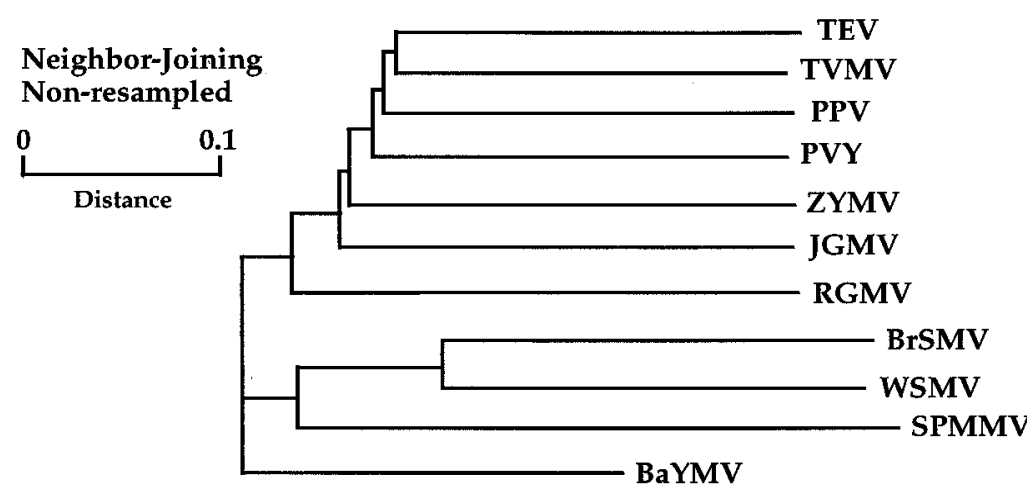

POTYVIRUS

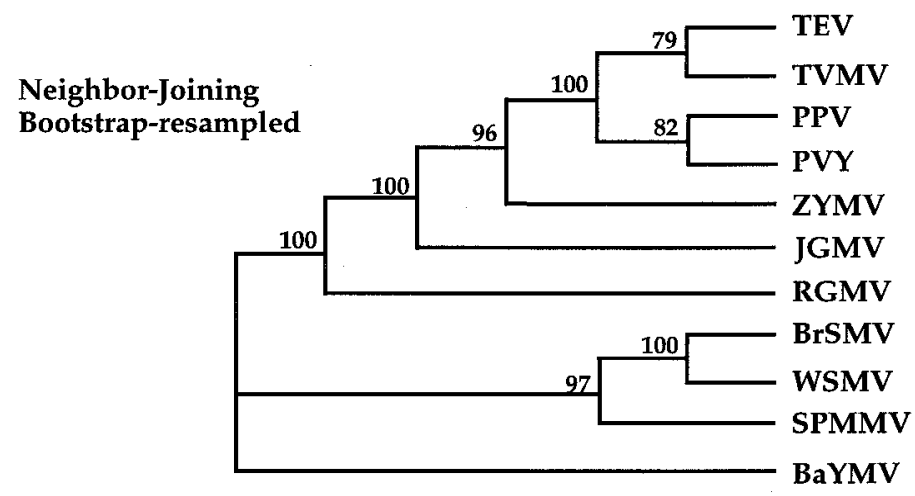

POTYVIRUS
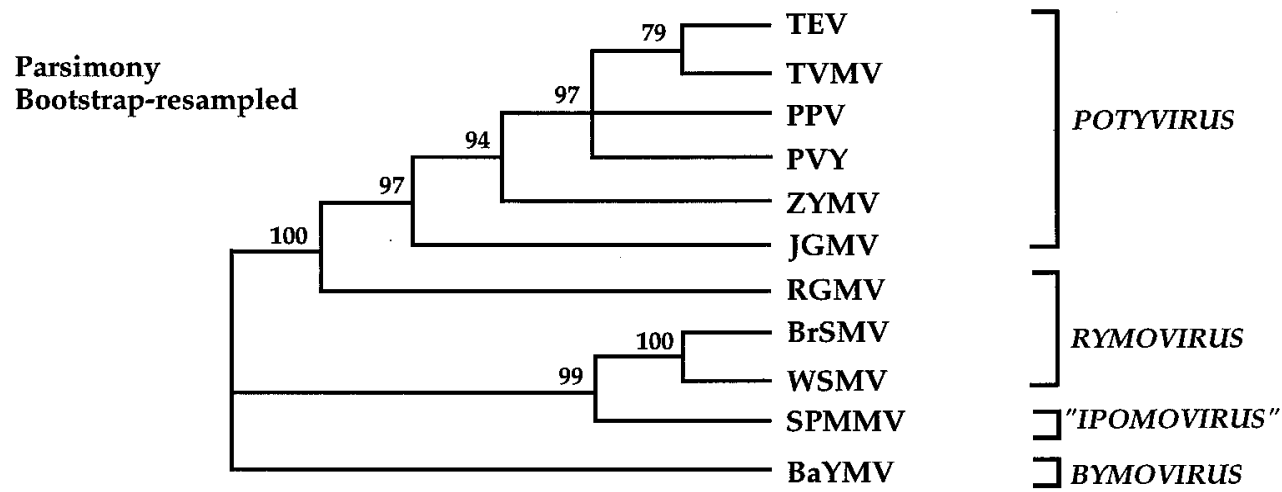

Fig. 3. Phylogenetic relationships among 11 species of the family Potyviridae, based on multiple alignment of complete polyprotein sequences. Trees were obtained by the neighbor-joining or parsimony methods, with barley yellow mosaic virus (BaYMV) RNA 1 defined as the outgroup. Horizontal branch lengths for the neighbor-joining tree, derived from the nonresampled data set, correspond to mean character distances between taxa; vertical lengths are arbitrary. Trees derived from bootstrap-resampled data sets (1,000 replications) are based on a 50\% majority-rule consensus, in which only tree topology is relevant; both vertical and horizontal branch lengths are arbitrary. Bootstrap percentages of clades are shown (when $>50 \%$ ) along internal branches of trees derived from bootstrap-resampled data sets. TEV $=$ tobacco etch virus; TVMV = tobacco vein mottling virus; $\mathrm{PPV}=$ plum pox virus; $\mathrm{PVY}=$ potato virus $\mathrm{Y} ; \mathrm{ZYMV}=\mathrm{zu}-$ cchini yellow mosaic virus; JGMV = Johnsongrass mosaic virus; RGMV = ryegrass mosaic virus; BrSMV = brome streak mosaic virus; WSMV = wheat streak mosaic virus; and SPMMV = sweet potato mild mottle virus. 
Potyvirus. Comparison of branch lengths obtained for SPMMV, using the neighbor-joining analyses (nonresampled data sets) of complete polyprotein or NIb protein sequences, indicated that SPMMV is no more similar to WSMV and BrSMV than RGMV is to any member of the genus Potyvirus.

\section{DISCUSSION}

Previous phylogenetic analyses $(6,16,27,29)$ of the genus Rymovirus used $\mathrm{CP}$ or partial $\mathrm{NIb}$ sequences to reconstruct evolutionary history. In these studies, AgMV and HoMV formed a clade with RGMV, whereas WSMV and BrSMV clustered in a separate clade. Based on phylogenetic analyses of full-length polyprotein or NIb protein sequences presented in the current study, it is clear that the genus Rymovirus, as presently defined, is not monophyletic. Although the neighbor-joining and parsimony methods utilize differ- ent assumptions to estimate phylogenetic relationships among taxa, both methods produced trees that place WSMV and BrSMV as sister taxa that do not share a most recent common ancestor with the type species of the genus Rymovirus (RGMV). Thus, evolution of the mite-transmission trait within the family Potyviridae is paraphyletic. How the capacity for mite-transmission arose within two lineages of the family Potyviridae remains an unanswered question, but we noted that transmission by eriophyid mites is not unique to potyviruses; several potex- and carla-like viruses are vectored by eriophyid mites (25). A similar situation exists within the aphid-transmitted viruses of the family Potyviridae. Recently, analysis of 3'-terminal sequences of narcissus latent and Maclura mosaic viruses indicate that these two aphid-transmitted viruses are more closely related to members of the genus Bymovirus than they are to members of the genus Potyvirus, as a result the genus "Macluravirus" has been proposed (5).

\section{CURRENT GENUS}

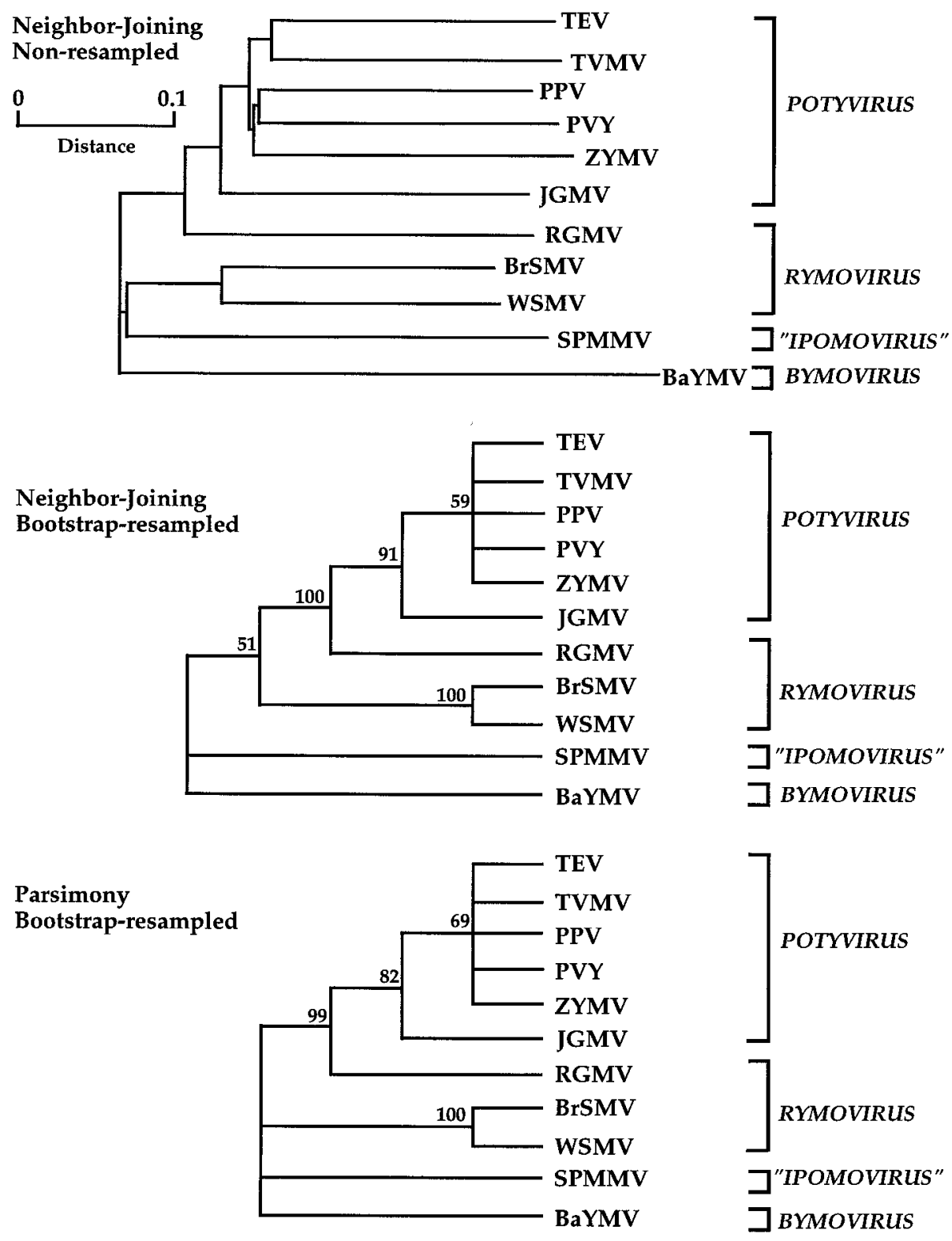

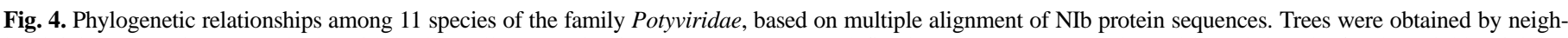

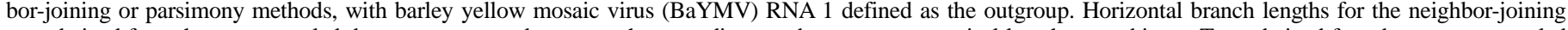

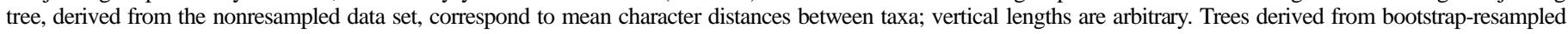

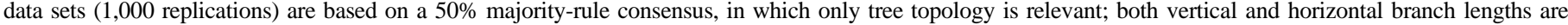

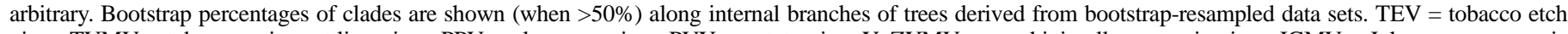

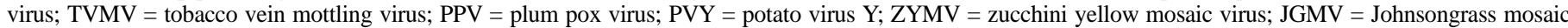
virus; RGMV = ryegrass mosaic virus; BrSMV = brome streak mosaic virus; WSMV = wheat streak mosaic virus; and SPMMV = sweet potato mild mottle virus. 
Sufficient data are available to split the current genus Rymovirus into two distinct genera. Because the partial nucleotide sequence data available for AgMV and HoMV indicate these potyviral genomes are closely related to $\operatorname{RGMV}(26,27)$, the genus Rymovirus should retain these three viruses as member species. WSMV and BrSMV, however, should be classified as something other than species of the genus Rymovirus. One possibility would be to place WSMV and BrSMV into the same genus as SPMMV, the potyviral genome with which WSMV and BrSMV share a most recent common ancestor. However, given the substantial sequence divergence between SPMMV and WSMV or BrSMV and the fact that SPMMV is transmitted by whiteflies, a separate genus for SPMMV is justified.

The International Committee on Taxonomy of Viruses (ICTV) currently is in the process of revising the taxonomy and nomenclature of the family Potyviridae. The ICTV Executive Committee recently approved the establishment of the genus "Tritimovirus," which contains WSMV (type species) and BrSMV as members (P. Berger, personal communication), and it is expected that this revision will appear in the next report from the ICTV. In addition, the recently discovered sugarcane streak mosaic virus (19) from Pakistan appears to be a close relative of WSMV and BrSMV (J. S. Hall, unpublished data) that may represent the third member species of the genus "Tritimovirus."

\section{ACKNOWLEDGMENTS}

We thank B. Adams for assistance with phylogenetic analyses.

\section{LITERATURE CITED}

1. Aleman-Verdaguer, M., Goudou-Urbino, C., Dubern, J., Beachy, R. N., and Fauquet, C. 1997. Analysis of the sequence diversity of the P1, HC, $\mathrm{P} 3$, NIb and $\mathrm{CP}$ genomic regions of several yam mosaic potyvirus isolates: Implications for the intraspecies molecular diversity of potyviruses. J. Gen. Virol. 78:1253-1264.

2. Allison, R. F., Johnson, R. E., and Dougherty, W. G. 1986. The nucleotide sequence of the coding region of tobacco etch virus genomic RNA: Evidence for the synthesis of a single polyprotein. Virology 154:9-20.

3. Atreya, C. D., Atreya, P. L., Thornbury, D. W., and Pirone, T. P. 1992. Site-directed mutations in the potyvirus HC-PRO gene affect helper component activity, virus accumulation, and symptom expression in infected tobacco plants. Virology 191:106-111.

4. Atreya, C. D., and Pirone, T. P. 1993. Mutational analysis of the helper component-proteinase gene of a potyvirus: Effects of amino acid substitutions, deletions, and gene replacement on virulence and aphid transmissibility. Proc. Natl. Acad. Sci. USA 90:11919-11923.

5. Badge, J., Robinson, D. J., Brunt, A. A., and Foster, G. D. 1997. 3'-terminal sequences of the RNA genomes of narcissus latent and Maclura mosaic viruses suggest that they represent a new genus of the Potyviridae. J. Gen. Virol. 78:253-257.

6. Berger, P. H., Wyatt, S. D., Shiel, P. J., Silbernagel, M. J., Druffel, K., and Mink, G. I. 1997. Phylogenetic analysis of the Potyviridae with emphasis on legume-infecting potyviruses. Arch. Virol. 142:1979-1999.

7. Brakke, M. K. 1987. Virus disease in wheat. Pages 585-603 in: Wheat and Wheat Improvement. 2nd ed. E. G. Heyne, ed. American Society of Agronomy, Crop Science Society of America, Soil Science Society of America, Madison, WI.

8. Brakke, M. K., Skopp, R. N., and Lane, L. C. 1990. Degradation of wheat streak mosaic virus capsid during leaf senescence. Phytopathology 80: 1401-1405.

9. Carrington, J. C., Cary, S. M., Parks, T. D., and Dougherty, W. G. 1989. A second proteinase encoded by a plant potyviral genome. EMBO J. 8:365-370.

10. Carrington, J. C., and Dougherty, W. G. 1988. A viral cleavage site cassette: Identification of amino acid sequences required for tobacco etch virus polyprotein processing. Proc. Natl. Acad. Sci. USA 85: 3391-3395.

11. Chenault, K. D., Hunger, R. M., and Sherwood, J. L. 1996. Comparison of the nucleotide sequence of the coat protein open reading frame of nine isolates of wheat streak mosaic rymovirus. Virus Genes 13:187-188.

12. Colinet, D., Krummert, J., and Lepoivre, P. 1996. Molecular evidence that the whitefly-transmitted sweet potato mild mottle virus belongs to a distinct genus of the Potyviridae. Arch. Virol. 141:125-135.

13. Domier, L. L., Franklin, K. M., Shahabuddin, M., Hellmann, G. M., Overmeyer, J. H., Hiremath, S. T., Siaw, M. F., Lomonossoff, G. P., Shaw, J. G., and Rhoads, R. E. 1986. The nucleotide sequence of tobacco vein mottling virus RNA. Nucleic Acids Res. 14:5417-5430.

14. Dougherty, W. G., Cary, S., and Parks, T. D. 1989. Molecular genetic analysis of a plant virus polyprotein cleavage site: A model. Virology 171:356-364.

15. Fröhlich, K.-U. 1994. Sequence Similarity Presenter: A tool for the graphic display of similarities of long sequences for use in presentations. Comput. Appl. Biosci. 10:179-183

16. Gotz, R., Huth, W., and Maiss, E. 1995. Molecular analyses of the coat protein region of different viruses on Poaceae belonging to the Potyviridae. Agronomie 15:491-494.

17. Gotz, R., and Maiss, E. 1995. The complete nucleotide sequence and genome organization of the mite-transmitted brome streak mosaic rymovirus in comparison to those of potyviruses. J. Gen. Virol. 76:2035-2042.

18. Gough, K. H., and Shukla, D. D. 1993. Nucleotide sequence of Johnsongrass mosaic potyvirus genomic RNA. Intervirology 36:181-192.

19. Jensen, S. G., and Hall, J. S. 1993. Identification of a new sorghum infecting species of potyvirus from sugarcane. (Abstr.) Phytopathology 83:884.

20. Kashiwazaki, S., Minobe, Y., Omura, T., and Hibino, H. 1990. Nucleotide sequence of barley yellow mosaic virus RNA 1: A close evolutionary relationship with potyviruses. J. Gen. Virol. 71:2781-2790.

21. Lane, L. C. 1986. Propagation and purification of RNA plant viruses. Methods Enzymol. 118:687-696.

22. Niblett, C. L., Zagula, K. R., Calvert, L. A., Kendall, T. L., Stark, D. M., Smith, C. E., Beachy, R. N., and Lommel, S. A. 1991. cDNA cloning and nucleotide sequence of the wheat streak mosaic virus capsid protein gene. J. Gen. Virol. 72:499-504.

23. Peerenboom, E., Prols, M., Schell, J., Steinbiss, H. H., and Davidson, A. D. 1992. The complete nucleotide sequence of RNA 1 of a German isolate of barley yellow mosaic virus and its comparison with a Japanese isolate. J. Gen. Virol. 73:1303-1308.

24. Robaglia, C., Durand-Tardif, M., Tronchet, M., Boudazin, G., AstierManifacier, S., and Casse-Delbart, F. 1989. Nucleotide sequence of potato virus Y (N Strain) genomic RNA. J. Gen. Virol. 70:935-947.

25. Ryabov, E. V., Generozov, E. V., Vetten, D. J., and Zariev, S. K. 1996. Nucleotide sequence of the 3 '-terminal region of mite-borne filamentous virus indicates its relation to the shallot virus X group. Mol. Biol. 30:6367

26. Salm, S. N., Rey, M. E. C., Robertson, N. L., French, R., Rabenstein, F., and Schubert, J. 1996b. Molecular cloning and nucleotide sequencing of the partial genomes of Agropyron and Hordeum mosaic viruses, two members of the Rymovirus genus in the taxonomic family Potyviridae. Arch. Virol. 141:2115-2127.

27. Salm, S. N., Rey, M. E. C., and Rybicki, E. P. 1996. Phylogenetic justification for splitting the rymovirus genus of the taxonomic family Potyviridae. Arch. Virol. 141:2237-2242.

28. Schaad, M. C., Haldeman-Cahill, R., Cronin, S., and Carrington, J. C. 1996. Analysis of the VPg-proteinase (NIa) encoded by tobacco etch potyvirus: Effects of mutations on subcellular transport, proteolytic processing, and genome amplification. J. Virol. 70:7039-7048.

29. Schubert, J., Rabenstein, F., and Proll, E. 1995. Sequence of the 3'-part of the RNA of ryegrass mosaic virus, a potyvirus. Agronomie 15:447-452.

30. Teycheney, P. Y., Tavert, G., Delbos, R., Ravelonandro, M., and Dunez, J. 1989. The complete nucleotide sequence of plum pox virus RNA (strain D). Nucleic Acids Res. 17:10115-10116.

31. Verchot, J., Koonin, E. V., and Carrington, J. C. 1991. The 35-kDa protein from the $\mathrm{N}$-terminus of the potyviral polyprotein functions as a third virus-encoded proteinase. Virology 185:527-535.

32. Ward, C. W., McKern, N. M., Frenkel, M. J., and Shukla, D. D. 1992. Sequence data as the major criterion for potyvirus classification. Pages 283-297 in: Potyvirus Taxonomy (Arch. Virol., Suppl. 5). O. W. Barnett, ed. Springer verlag, Vienna.

33. Ward, C. W., Weiller, G. F., Shukla, D. D., and Gibbs, A. 1995. Molecular systematics of the potyviridae, the largest plant virus family. Pages 477-500 in; Molecular Basis of Virus Evolution. A. J. Gibbs, C. H. Calisher, and F. Garcia-Arenal, eds. Press Syndicate of the University of Cambridge, Cambridge.

34. Wisler, G. C., Purcifull, D. E., and Hiebert, E. 1995. Characterization of the $\mathrm{P} 1$ protein and coding region of the zucchini yellow mosaic virus. J. Gen. Virol. 76:37-45.

35. Yang, Z. N., and Mirkov, T. E. 1997. Sequence relationships of sugarcane mosaic and sorghum mosaic virus strains and development of RTPCR-based RFLPs for strain discrimination. Phytopathology 87:932-939.

36. Zagula, K. R., Niblett, C. L., Robertson, N. L., French, R., and Lommel, S. A. 1992. Potyviridae: Genus Rymovirus. Arch. Virol. (Suppl. 5):269-276. 